ISSN: 2536-5339

\title{
Sirkadiyen Ritmin Anaerobik Güç Üzerine Etkisinin İncelenmesi
}

\author{
Nurten DiNÇ ${ }^{1} \quad$ Ümit HAYTA ${ }^{2}$ \\ ${ }^{1}$ Manisa Celal Bayar Üniversitesi, Spor Bilimleri Fakültesi, MANiSA \\ ${ }^{2}$ Manisa Celal Bayar Üniversitesi, Sağlık Bilimleri Enstitüsü, Antrenörlük Eğitimi, MANiSA
}

Künye: Dinç, N. ve Hayta, Ü. (2018). Sirkadiyen Ritmin Anaerobik Güç Üzerine Etkisinin İncelenmesi. Gaziantep Üniversitesi Spor Bilimleri Dergisi, 3(4): 77-86.

\section{Öz}

Bu çalışmada da sirkadiyan ritmin gün içinde 3 farklı zaman diliminde yapılan dikey sıçrama ve 40 metre sprint performansı üzerine etkisinin araştııılması amaçlanmıştır. Manisa Celal Bayar üniversitesi Spor Bilimleri Fakültesinde öğrenim gören yaş, boy, kilo ve vücut kitle indeksleri sırasıyla; $21,5 \pm 1,60 \mathrm{yıl}, 178,7 \pm 5,30 \mathrm{~cm}, 74,9 \pm 7,2 \mathrm{~kg}$, $23,27 \pm 1,95 \mathrm{~kg} / \mathrm{m}^{2}$ olan 14 öğrenci çalışmaya gönüllü olarak katılmıştır. Çalışmaya katılan katılımcıların gün içinde 09:00, 12:00 ve 15:00 saatlerinde 40 metre sprint ve dikey sıçrama verileri alınmıştır. Her test 2 defa uygulanmış ve en iyi test skoru seçilmiştir. Elde dilen veriler SPSS 23 paket programın da tekrarlayan ölçümlerde Anova testi kullanılarak analiz edilmiştir. Anlamlılık değeri $p<0,05$ olarak alınmıştır. Çalışma verilerinin analizi sonucunda saat 09:00 ve 12:00 de alınan sıçrama testi sonuçları arasında istatistiksel olarak anlamlı bir farklılık bulunurken $(p<0,05)$ saat 09:00 ve 15:00 da alınan sıçrama testi sonuçları arasında istatistiksel olarak anlamlı bir fark saptanmamıştır $(p>0,05)$. Ancak saat $12: 00$ ve 15:00'te alınan sıçrama test sonuçları arasında istatistiksel olarak anlamlı fark bulunmuştur $(p<0,05)$. Saat 09.0012.00 ve $15: 00$ de alınan 40 metre sprint koşuları arasında istatistiksel olarak anlamlı bir farklılık bulunmamıştır $(p>0,05)$. Sonuç olarak gün içindeki farklı zaman dilimlerinin sıçrama performansı üzerine etkisi olduğu görülürken, 40 metre sprint üzerine bir etkisi olmadığı gözlemlenmiştir. Hormonel, beslenme, stress, gibi faktörlerin gün içindeki farklı zaman dilimlerinde yapılan performansa etkileri olduğu bilinmektedir. Ayrıca katılımcıların sedanter birey olmasının sprint teknikleri ve 40 metre sprint performansını etkilediği düşünülmektedir.

\section{Orijinal Makale}

Yayın Bilgileri

Gönderi Tarihi: 01.11.2018

Kabul Tarihi: 03.12.2018

Yayın Tarihi: 28.12.2018

Sorumlu Yazar

e-mail: nurten.dinc@hotmail.com

DOI: $10.31680 / g a u n j s s .477535$

Anahtar Kelimeler: Anaerobik güç, Dikey sıçrama, Sirkadiyen ritim

\section{Investigation of The Effect of Circadian Rhythm on Anaerobic Power}

\begin{abstract}
In this study, it was aimed to investigate the effect of 40 meters sprint performance and vertical jump in 3 different time periods. 14 students at Celal Bayar University, whose age, height,weight body mass indexes are in order; 21,5 $\pm 1,60 \mathrm{yll}, 178,7 \pm 5,30$ $\mathrm{cm}, 74,9 \pm 7,2 \mathrm{~kg}, 23,27 \pm 1,95 \mathrm{~kg} / \mathrm{m}^{2}$, participated to the work voluntarily. Participants' sprint and vertical jumping data for 40 meters at 09:00, 12:00 and 15:00 during the day were taken. Each test was applied twice and the best test score was selected. The data obtained were analyzed using the Repeated measure Anova method of the Spss 23 package program. The significance value was taken as $p<0.05$. While a statistically significant difference $(p<0,05)$ was found between the jumping test results obtained at 09:00 and 12:00 as a result of the study data, there was no statistically significant difference between the results of the jump test taken at 09:00 and 15:00 $(p>0,05)$. However, a statistically significant difference was found between the jump test results taken at 12:00 and 15:00 $(p<0,05)$. A statistically significant difference was not found between the sprint conditions at 40 meters and 09.00-12.00 and 15.00 hours $(p>0,05)$. As a result, while it is seen that different time periods in the day have an impact on splash performance, it is observed that there is no effect on 40-m sprint. Factors such as hormonal, nutritional, stress, etc. are known to have effects on performance over different time periods. In addition, it is thought that the participants being sedentary affect sprinting techniques and sprint performance of 40 meters.
\end{abstract}

\section{Original Article}

\section{Article Info}

Received: 01.11.2018

Accepted: 03.12.2018

Published: 28.12 .2018

\section{Corresponding Author}

e-mail: nurten.dinc@hotmail.com 


\section{Giriş}

Spor performansı zihinsel ve fizyolojik aktiviteleri etkileyen insan biyolojik ritmine bağlıdır. Spor performansı bileşenlerinden olan kas kuvveti ve kısa süreli yüksek güç çıkışı, gün içinde ki zamanlarda sinüzoidal bir şekilde değişir ve vücut sıklığının maksimuma yakın olduğu akşam saatlerinde zirve değerlere ulaşır (Atkinson ve Reilly 1996). Belirli bir zaman biriminde belli aralıklarla düzenli olarak tekrar eden döngüsel değişimler biyolojik ritim, bir güneş günüyle ilişkili olarak oluşan döngüsel değişimler ise sirkadiyen ritim olarak bilinmektedir (Relly ve Waterhouse, 2000; Kinişler, 2005). Diğer bir tanıma göre; sirkadiyen ritim, yaklaşık 24 saatlik döngüsel periyotlarda devam eden ve çok çeşitli fizyolojik sistemlere etki gösteren endojen biyoritimlerdir (Hadley ve Levine 2006; Hatfield ve ark.,2016). Sadece bu tanımlara bakılarak bireysel ve takım sporlarında kuvvet antrenman saatlerinin planlanmasın da birçok antrenörler ve kondisyonerlere bir fikir verebilir. Sirkadiyen ritmin varlığı insanın fiziksel performansında, sporcu antrenmanlarında ve yarışmalarda potansiyal etkilere sahiptir. Birçok performans göstergesi vücut sıcaklığındaki sirkadiyen değişimleri takip etmektedir (Reilly ve Bambaeichi, 2003). Vücut sıcaklığı sirkadiyen ritmin bir göstergesi olarak kullanılabilir (Waterhouse ve ark., 2005). Spor performansında endojen ve ekzojen mekanizmaların sirkadiyen ritimlere olan göreceli etkisi ile ilgili tartışmalara rağmen, spor performansının normal gündelik şartlarda günün saatine göre değişmesi durumunda, bunun sporcu üzerinde doğrudan etkisi olduğu söylenebilir (Drust ve ark., 2005). Bu etkileri anlamak ve bu etkileri araştırmak sporcu performansının gelişiminin yanı sıra hem bireysel hem de takım sporlarındaki başarılara kuşkusuz etkisi olacaktır.

Spor performansındaki birçok fizyolojik ve davranışsal değişkende sirkadiyen bazlı dalgalanmalar gözlemlenmiştir (Drust ve ark., 2005). Literatürde yapılan çalışmalarda sirkadiyen ritmin günün farklı saatlerindeki kısa süreli atletik performansa etki ettiği doğrulanmıştır (Gauthier ve ark., 2001; Guette ve ark., 2005). Egzersiz performansı, anaerobik egzersiz kapasitesi ve bacağın diz ekstansör kaslarının izometrik torku, 24 saatlik dilimde belirgin varyasyonlar sergilemekte ve akşamın erken saatlerinde zirve seviyelere ulaşmaktadır (Callard ve ark., 2000; Souissi ve ark., 2004). Bu bağlamda en iyi kısa vadeli performansların, günün sabah saatleri ve öğleden sonra maksimum değerlere ulaştığı liteartürde yer almaktadır (Souissi ve ark., 2007; Souissi ve ark., 2010).Yüksek yoğunluklu kısa süreli egzersizlerde (ör: kas gücü, sprint) bu günlük sirkadiyen varyasyonlar, test edilen 
popülasyona, kas gruplarına ve deneysel tasarıma bağlı olarak \% 3 ila \% 21,2 arasında değişmektedir (Nicolas ve ark., 2007).

$\mathrm{Bu}$ çalışmada da sirkadiyan ritmin gün içinde 3 farklı zaman diliminde ki 40 metre ve dikey sıçrama üzerine etkisinin araştırılması amaçlanmıştır.

\section{Yöntem}

Çalışmaya Manisa Celal Bayar Üniversitesi Spor Bilimleri Fakültesinde okuyan rastgele seçilmiş 14 kişi gönüllü olarak katılmıştır.

Katılımcıların öncelikli olarak, yaş, boy, kilo ve vücut kitle indeksleri (VKI) belirlenmiştir. Katılımcılar aynı gün içinde farklı zaman aralıklarında (09.00- 12.00 ve 15.00) dikey sıçrama ve 40 metre sprint testlerine katılmışlardır. Katılımcılar her test öncesinde 5 dakikalık düşük şiddetli koşu ve streching ile ısınmalarını tamamlamışlardır. Dikey sıçrama testi ve 40 metre testi 3 dakikalık dinlenmelerle 2 defa tekrarlamış ve 2 skordan en yüksek değer test skoru olarak alınmıştır.

\section{Dikey Sıçrama ve Anaerobik Güç Ölçümü}

Anaerobik güç ölçümleri, dikey sıçrama testi ile yapılmıştır. Bu ölçümde gönüllünün ayakta uzanabildiği yükseklik ile sıçrayarak dokunabileceği nokta arasındaki mesafe cm cinsinden ölçülmüş ve forma kaydedilmiştir (Tamer, 1995). Daha sonra deneklerin vücut ağırlıklarından da yararlanılarak aşağıda verilen Lewis Formülü ile anaerobik güçleri hesaplanmıştır (Ağar, 2006).

$$
\begin{aligned}
& P=\sqrt{ } 4,9 .(\mathrm{W}) . \sqrt{ } \mathrm{D} \\
& P=\text { Anaerobik Güç }(\mathrm{kgm} / \mathrm{sn}) \quad \mathrm{W}=\text { Vücut Ağırlığı }(\mathrm{kg}) \\
& D=\text { Sıçrama Mesafesi }(\mathrm{cm}) \quad \sqrt{ } 4,9=\text { Sabit Sayı }(\mathrm{sn})
\end{aligned}
$$

\section{Metre Sprint Testi}

Katılımcılar kauçuk zeminli kapalı bir alanda 40 metre sprint performansını sergilemiştir. Test iki defa tekrarlanmış ve en iyi skor test skoru olarak kabul edilmiştir. Sprint testleri arasında 3 dakika dinlenme verilmiştir. Katılımcıların sprint süresi (Brower Timing Systems, Draper, UT) fotosel kullanılarak kaydedilmiştir.

\section{Veri Analizi}

Çalışmada SPSS 23 paket programıyla kullanılarak veriler tekrarlayan ölçümlerde Anova testi ile analiz edilmiştir. Günün zaman dilimleri arasında ki 
anaerobik güç farklılıklarını ortaya koyabilmek için Bonferroni testi uygulanmıştır. Tüm çalışma süresince kullanılan anlamlılık düzeyi $p<0.05$ olarak kabul edilmiştir.

\section{Bulgular}

Katılımcıların gün içindeki saat 09:00, 12:00 ve 15:00 te alınan anaerobik güç ve 40 metre Sprint test ortalamaları Tablo1'de verilmiştir.

Tablo 1: Katılımcıların günün farklı zamanlarında ki anaerobik güç ve $40 \mathrm{~m}$ sprint ortalamaları

\begin{tabular}{cccccc}
\hline \multicolumn{3}{c}{ Anaerobik güç ort-ss } & \multicolumn{3}{c}{$\mathbf{4 0}$ metre Sprint ort-ss } \\
\hline 9.00 & 12.00 & 15.00 & 9.00 & 12.00 & 15.00 \\
$1018.00 \pm 139,1$ & $735.2 \pm 126,9$ & $1023.77 \pm 138,1$ & $5.78 \pm 0.46 \mathrm{sn}$ & $5.8 \pm 0.45 \mathrm{sn}$ & $5.79 \pm 0.52 \mathrm{sn}$ \\
\hline \multicolumn{3}{c}{ Katılımcıların gün içindeki saat 09:00, 12:00 ve $15: 00$ te alınan anaerobik güç }
\end{tabular}
ve 40 metre Sprint test ortalamaları değerleri arasındaki fark benferroni analizi ile gerçekleştirilerek sonuçlar Tablo 2'de verilmiştir.

Tablo 2: Farklı zamanlardaki anaerobik güç testi bonferroni sonuçları

\begin{tabular}{cc|ccc}
\hline (I) AG & (J) AG & I-L ortalama fark & $\begin{array}{c}\text { Standart } \\
\text { hata }\end{array}$ & $\boldsymbol{p}$ \\
\hline 1 & 2 & $283.538^{*}$ & 19.435 & $.000^{* *}$ \\
& 3 & 17.047 & 25.277 & 1.000 \\
2 & 1 & $-283.538^{*}$ & 19.435 & $.000^{\star *}$ \\
& 3 & $-266.491^{*}$ & 27.762 & $.000^{* *}$ \\
3 & 1 & -17.047 & 25.277 & 1.000 \\
& 2 & $266.491^{*}$ & 27.762 & $.000^{* *}$ \\
\hline
\end{tabular}

AG: Anaerobik Güç, 1=09.00, 2=12.00, 3= $15.00 \mathrm{P}<0,05^{* *}$

Tablo 2'deki Bonferroni sonuçları incelendiğinde; saat 09:00 da alınan anaerobik güç sonuçları ile saat $12: 00$ de alınan anaerobik güç sonuçları karşılaştırıldığında, saat 09:00 da alınan test sonuçlarının istatistiksel olarak daha yüksek bulunurken $(p<0,05)$, saat 09:00 ve 15:00 da alınan anaerobik güç sonuçları arasında istatistiksel olarak anlamlı bir farklılık bulunmamıştır $(p>0,05)$. Ancak saat 12:00 ve 15:00 de alınan test sonuçları karşılaştırıldığında ise saat 15:00'te alınan test sonuçlarının saat 12:00 ye göre istatistiksel olarak daha yüksek saptanmıştır $(p<0,05)$.

Katılımcıların gün içindeki saat 09:00, 12:00 ve 15:00 te alınan 40 metre sprint değerleri arasındaki fark benferroni analizi ile gerçekleştirilerek sonuçlar Tablo 3'de verilmiştir. 
Tablo 3: Farklı zamanlardaki 40 Metre Sprint Test Bonferroni Sonuçları

\begin{tabular}{cc|ccc}
\hline & & \multicolumn{3}{c}{ Standart } \\
(I) kosu & (J) kosu & I-L Ortalam fark & Hata & $p$ \\
\hline 1 & 2 & -.020 & .051 & 1.000 \\
\hline \multirow{2}{*}{2} & 3 & -.011 & .054 & 1.000 \\
& 1 & .020 & .051 & 1.000 \\
3 & 3 & .009 & .071 & 1.000 \\
& 1 & .011 & .054 & 1.000 \\
\hline \multicolumn{2}{c}{2} & -.009 & .071 & 1.000 \\
\hline \multicolumn{2}{c}{$2=09.00,2=12.00,3=15.00, \mathrm{P}<0,05^{* *}$} & &
\end{tabular}

Tablo 3'deki Bonferroni sonuçları incelendiğinde günün farklı zamanlarında ki 40 metre sprint test skorları arasında istatistiksel olarak anlamlı bir farklılık bulunmamıştır $(p>0,05)$.

\section{Tartışma ve Sonuç}

Çalışmamızda sedanter katılımcılarda günün farklı zamanlarında alınan dikey sıçrama değerlerinin istatistiksel olarak anlamlı değişiklik gösterdiği saptanırken, farklı zamanlarda alınan 40 metre sprint test değerlerinde istatistiksel olarak anlamlı farklılık olmadığı gözlenmiştir. Anaerobik gücü belirlemek için saat 09:00 ile 12:00 saatlerinde yapılan dikey sıçrama test sonuçları arasında ki farka bakıldığında saat 09:00 da alınan test sonuçlarının istatistiksel olarak daha yüksek olduğu $(p<0.05)$, ayrıca saat 12:00 ile 15:00'te alınan anaerobik güç test sonuçlarına bakıldığında saat 15:00'te alınan test sonuçlarının istatistiksel olarak daha yüksek olduğu saptanmıştır $(p<0.05)$. Saat 09:00 ile 15:00'te alınan anaerobik güç değerleri karşılaştırıldığında ise istatistiksel olarak anlamlı bir farka rastlanmamıştır ( $p>0.05)$.

Literatür incelendiğinde; Deschenes ve ark. (1998)'nın yaptığı çalışmada maksimum kas performansının, egzersizin gerçekleştiği (08:00 ve 20:00) günün segmentleri arasında değiştiğini, ancak bu değişimin hareket hızına özgü olduğunu gösterirken, Hatfield ve ark. (2016) farklı egzersiz şiddetinde (\% 30, \% 60 \% 90) ve zaman noktalarında yapılan $(04: 00,10: 00,16: 00$ ve 22:00) bech press ve squat jump testinde zaman noktaları arasında azalma görülmemesine karşın 1 tekrar maksimaller de yüzdesel olarak farklılıklar olsa da, bunların sirkadiyen ritimden etkilenmediğini bildirirken, bu yüksek kuvvet ve güç egzersizlerinin akut performansta azalmalar olmadan günün herhangi bir saatinde gerçekleştirilebileceğini bildirmiştir. Buna karşın Teo ve ark., (2011) yaptığı çalışmada sirkadiyen ritmin kuvvet ve güç 
Çıktısının üzerine önemli farklılıklar olduğunu bildirmiştir. Hatfield ve ark., (2016) çalışması bu çalışmanın anaerobik güç sonuçları ile benzerlik göstermezken Teo ve ark., (2011) yaptığı çalışma ile Deschenes ve ark., (1998) yaptığı çalışma sonuçları bu çalışma verileriyle örtüşmektedir. Bu çalışmada alınan 40 metre sprint performans testinde, zamanlar arasında anlamlı bir fark çıkmamasının, katıımcıların sedanter birey olmaları ve koşu mekaniğini bilmemelerinden kaynaklandığı düşünülmektedir.

Guette ve ark., (2005) yaptığı çalışmada günün farklı saatlerinde dominant ve non dominant quadriceps femorus maksimum istemli kasılmada saat 18:00 da her iki bacağın zirve güç (tork) değerinin istatistiksel olarak anlamlı derecede en yüksek olduğunu bildirmesine ek olarak, Küüsmaa ve ark., (2015) çalışmasında sabah ve akşam gruplarının maksimal istemli kasılma seviyelerini incelemiş ve akşam grubu lehine anlamlı farklıık bulunduğunu göstermiştir. Ayrıca Lericollais ve ark., (2009) wingate anaerobik güç testi sırasında gözlemlenen zirve güç ve ortalama gücün saat 18:00'da saat 06:00'dan daha yüksek olduğunu bildirmiştir. Yapılan çalışmalarda öğleden sonraki saatlerde alınan zirve güç ve maksimal istemli kasılma değerlerinin sabah saatlerine göre daha yüksek çıkması bu çalışmadaki sonuçlarla örtüşmemektedir. Bu çalışmada saat 09:00 ve 15:00'te alınan dikey sıçrama test sonuçları arasında istatistiksel olarak anlamlı bir farklılık bulunmazken saat 12:00 ile 15:00'te alınan test sonuçlarına bakıldığında saat 15:00'te alınan dikey sıçrama değerlerinin istatistiksel olarak daha yüksek olduğu gözlenmiştir. Bu çalışmada uygulanan test protokolleri ve katılımcılar bakımından farklılık göstermekle birlikte çevresel ısının kassal performans üzerinde etkisinin olduğu düşünülmektedir.

Bu çalışmalardan farklı olarak Chtourou ve ark., (2012) 12 haftalık alt ekstremite kuvvet antrenmanı ve 2 haftalık taper antrenmanı şeklinde programlanan çalışmasında, sabah ve akşam gruplarında akşam grubu lehine farklılık gözlemlemişlerdir. Ayrıca Chtourou ve ark., (2012) ${ }^{\mathrm{b}} 8$ haftalık alt ekstremite kuvvet antrenmanı sonrası sabah ve akşam gruplarında ki günlük kuvvet farklılıklarını incelediği çalışmasında kuvvet antrenmanı öncesi, sabahtan akşama doğru kuvvet artışında önemli artışlar olduğunu belirtirken antrenman sonrası anaerobik güçteki günlük farklılıkların köreldiğini ve sabah ve akşam arasındaki anlamlı bir farklılı̆ın olmadığını bildirmiştir. Chtourou ve ark., (2012) ${ }^{a, b}$ 'nın çalışmalarının prosedür bakımından farklı olmasının yanında bu çalışmada da sabah ve öğleden sonra yapılan anaerobik test sonuçları arasında bir anlamlı bir farklııık görülmemiştir. Ancak 
öğlen ve öğleden sonraki dikey sıçrama değerlerin de öğleden sonra lehine anlamlı farklılık gözlemlenmiştir.

Çevre koşullarının etkisinin incelendiği, Racinais ve ark., (2004)'nın sabah 07:00-09:00 ve öğleden sonra 17:00-19:00 saatleri arasında nötr ve orta derece sıcaklıktaki çevresel koşullarda uygulanan squat jump (SJ) ve counter-movement jump (CMJ) testlerinde; aynı kişilerin test sırasında ki ortam sıcaklığına bağı olarak günün farklı saatlerinden etkilendiğini, kassal performansın sadece nötür koşullarda etkilendiğini, ılık ve nemli durumun kassal performanstaki günlük değişimi körelttiğini ve ortam sıcaklığının etkisinin zamana bağlı olarak değiştiğini bildirmesine ek olarak sıcak bir çevre de hem SJ hem de CMJ performansın öğleden sonraya göre sabah önemli ölçüde yüksek olduğunu belirtmişlerdir. Çevresel sıcaklık veya egzersiz sonucu, kas sistemi ve core bölgesindeki sıcaklık değişimleri egzersiz performansını etkilemektedir (Watherhouse, 2005).

Bu çalışmada saat 09:00 ve 15:00 te alınan anaerobik güç değerleri arasında istatistiksel olarak anlamlı bir farka rastlanmamakla birlikte saat 09:00 da alınan dikey sıçrama sonuçları ile saat $12: 00$ de alınan dikey sıçrama sonuçları karşılaştııılığında, saat 09:00 da alınan test sonuçlarının istatistiksel olarak daha yüksek olduğu saptanmıştır. Sabah alınan dikey sıçrama değerlerinin öğle saatine göre istatistiksel olarak daha yüksek çıkması kişilerin dinlenik olması, glikojen ve kretain fosfat depolarının dolu olmasına bağlanabilir. Diğer yandan saat 12:00 ve 15:00'te alınan test sonuçları karşılaştırıldığında ise saat 15:00'te alınan test sonuçlarının saat 12:00 ye göre istatistiksel olarak daha yüksek olduğu bulunmuştur. Öğleden sonra alınan dikey sıçrama değerlerinin öğle saatlerine göre daha yüksek çıkmasında ise; öğleden sonra değişen hormonal salınımların ve vücut sıcaklığının kassal performansta artışa sebep olarak anaerobik gücü etkilediği düşünülmektedir.

Literatürdeki araştırmalar da öğleden sonraki saatlerde kassal performansın yüksek çıkması ya da herhangi bir etkinin görülmemesi ya da tam aksine sabah performansın yüksek çıkması sirkadiyen ritmin performansa etkisini tam olarak açıklayamamaktadır. Çünkü uyku düzeyi, beslenme, stress, hormonal yanıtlar gibi bazı faktörlerin sirkadiyen ritim üzerinde etkileri olduğu bilinmektedir. Ayrıca sirkadiyen ritim fiziksel olarak fit olan bireylerde sedanter bireylere göre daha yüksek gözlenmektedir (Atkinson, 1996). İleride yapılacak olan çalışmalarda bu faktörlerin dikkate alınmasının yanında günün zaman dilimlerinin değişiklik göstermesi ve 
zaman aralıklarının arttırılması ayrıca farklı katılımcı grupları ile farklı performans testlerinin uygulanabilirliği önerilmektedir.

\section{Kaynakça}

Ağar, E. (2006). 9-11 Yaş erkek çocuklarda ip atlama ve interval koşu egzersizlerinin performans ile etkileşimi. ABÜ Sağlık Bilimler Enstitüsü Antrenörlük Eğitimi Anabilim Dalı, Yüksek Lisans Tezi, ss. 47. Bolu.

Atkinson, G., \& Reilly, T. (1996). Circadian variation in sports performance. Sports medicine, 21(4), 292-312.

Callard, D., Davenne, D., Gauthier, A., Lagarde, D., Van Hoecke, J. (2000). Circadian rhythms in human muscular efficiency: continuous physical exercise versus continuous rest. A crossover study. Chronobiol. Int. 17(5):693-704.

Chtourou, H., Chaouachi, A., Driss, T., Dogui, M., Behm, D. G., Chamari, K., \& Souissi, N. (2012). The effect of training at the same time of day and tapering period on the diurnal variation of short exercise performances. The Journal of Strength \& Conditioning Research, 26(3), 697-708.

Chtourou, H., Driss, T., Souissi, S., Gam, A., Chaouachi, A., \& Souissi, N. (2012) ${ }^{\text {. }}$ The effect of strength training at the same time of the day on the diurnal fluctuations of muscular anaerobic performances. The Journal of Strength \& Conditioning Research, 26(1), 217-225.

Deschenes, M. R., Kraemer, W. J., Bush, J. A., Doughty, T. A., Kim, D., Mullen, K. M., \& Ramsey, K. (1998). Biorhythmic influences on functional capacity of human muscle and physiological responses. Medicine and science in sports and exercise, 30(9), 1399-1407.

Drust, B., Waterhouse, J., Atkinson, G., Edwards, B., \& Reilly, T. (2005). Circadian rhythms in sports performance-an update. Chronobiology international, 22(1), 21-44.

Gauthier A, Davenne D, Martin A, Van Hoecke J. (2001). Time-of-day effects on isometric and isokinetic torque developed during elbow flexion in humans. Eur. J. Appl. Physiol. 84(3):249-252.

Guette M, Gondin J, Martin A. (2005). Time-of-day effect on the torque and neuromuscular properties of dominant and non-dominant quadriceps femoris. Chronobiol. Int. 22(3):541-558. 
Hadley, M and Levine, J. (2006),Endocrinology (6th ed.). Upper Saddle River, NJ: Pearson Prentice Hall.

Hatfield, D. L., Nicoll, J. X., \& Kraemer, W. J. (2016). Effects of circadian rhythm on power, force, and hormonal response in young men. The Journal of Strength \& Conditioning Research, 30(3), 725-732.

Kinişler, A. (2005). Anaerobik performansta sirkadiyen değişimlerin incelenmesi. Spor Bilimleri Dergisi, 16(4), 174-184.

Küüsmaa, M., Sedliak, M., \& Häkkinen, K. (2015). Effects of time-of-day on neuromuscular function in untrained men: Specific responses of high morning performers and high evening performers. Chronobiology international, 32(8), 1115-1124.

Lericollais, R., Gauthier, A., Bessot, N., Sesboüé, B., \& Davenne, D. (2009). Time-ofday effects on fatigue during a sustained anaerobic test in well-trained cyclists. Chronobiology international, 26(8), 1622-1635.

Nesser, T. W., Latin, R. W., Berg, K., \& Prentice, E. (1996). Physiological determinants of 40 -meter sprint performance in young male athletes. Journal of strength and conditioning research, 10, 263-267.

Nicolas, A., Gauthier, A., Michaut, A., \& Davenne, D. (2007). Effect of circadian rhythm of neuromuscular properties on muscle fatigue during concentric and eccentric isokinetic actions. Isokinetics and exercise science, 15(2), 117-129.

Racinais, S., Hue, O., \& Blonc, S. (2004). Time-of-day effects on anaerobic muscular power in a moderately warm environment. Chronobiology international, 21(3), 485-495.

Reilly, T. (1990). Human circadian rhythms and exercise. Critical reviews in biomedical engineering, 18(3), 165-180.

Reilly, T., Atkinson, G., \& Waterhouse, J. (2000). Chronobiology and physical performance. Exercise and sport science, 24, 351-72.

Souissi, N., Bessot, N., Chamari, K., Gauthier, A., Sesboüé, B., \& Davenne, D. (2007). Effect of time of day on aerobic contribution to the 30-s Wingate test performance. Chronobiology international, 24(4), 739-748.

Souissi, N., Driss, T., Chamari, K., Vandewalle, H., Davenne, D., Gam, A., ... \& Jousselin, E. (2010). Diurnal variation in Wingate test performances: influence of active warm-up. Chronobiology international, 27(3), 640-652. 
Souissi, N., Gauthier, A., Sesboue, B., Larue, J., Davenne, D. (2004). Circadian rhythms in two types of anaerobic cycle leg exercise: force-velocity and 30-s Wingate tests. Int. J. Sports Med. 25(1):14-19.

Tamer, K. (1995). Sporda fiziksel-fizyolojik performansının ölçülmesi ve değerlendirilmesi. Ankara; Türkerler Kitabevi, ss:4,25,40,124,124,132,158.

Teo, W., McGuigan, M. R., \& Newton, M. J. (2011). The effects of circadian rhythmicity of salivary cortisol and testosterone on maximal isometric force, maximal dynamic force, and power output. The Journal of Strength \& Conditioning Research, 25(6), 1538-1545.

Waterhouse, J., Drust, B., Weinert, D., Edwards, B., Gregson, W., Atkinson, G., ... \& Reilly, T. (2005). The circadian rhythm of core temperature: origin and some implications for exercise performance. Chronobiology international, 22(2), 207225. 